\title{
KOMUNIKASI INTERPERSONAL GURU DALAM MENINGKATKAN KEPERCAYAAN SISWA PADA BIMBINGAN BELAJAR ONMA DI KOTA BENGKULU
}

\author{
Oleh: \\ SAPTA SARI \\ Program Studi Ilmu Komunikasi Fakultas Ilmu-Ilmu Sosial \\ Universitas Dehasen Bengkulu
}

\begin{abstract}
The development of tutoring or bimbel does not only occur in big cities but also in the city of Bengkulu. Like Primagama, Ganesha, Talenta, and Onma. One of the tutoring in Bengkulu City is Onma. Onma Foundation is an institution that aims to help the government to realize a society that has competitive value in the world of education and the labor market, especially in Bengkulu Province. Up to now the addressable guidance institution on Mayjend street. Soetoyo No. 25 Tanah Patah Sub-District of Bengkulu City is still one of the partners of the Provincial Government and the City of Bengkulu to realize Bengkulu City Students. The ability and trust of students studying at Onma is influenced by the quality of the teacher. Teachers who are confident and have good interpersonal communication with their students will make students more quickly master the subject matter and they also have confidence in themselves that they are able to complete the tasks given by the teacher in tutoring. In this case, the teacher plays a very important role in increasing students' trust in their guidance teacher. Given that there are still many high school students in the city of Bengkulu not yet fully have good beliefs and morals even though in the field of academic achievement they excel, like Public High School 05 City students Bengkulu. The purpose of this study was to examine the process of tutoring for students through interpersonal communication between teachers and students which has a relationship with the level of trust possessed by high school students 05 City of Bengkulu who are currently attending the tutoring process at Onma Bengkulu.
\end{abstract}

Keywords: teacher, Onma, tutoring

\section{PENDAHULUAN}

Interaksi antara guru dengan siswa hampir berlangsung setiap hari. Guru selalu berkomunikasi dan berhadapan dengan siswa baik sekolah maupun di tempat bimbingan belajar. Interaksi ini merupakan komunikasi interpersonal, karena komunikasi yang dilakukan bersifat dialogis yang memungkinkan adanya pertukaran informasi dan feed back antara guru dengan siswa. Komunikasi yang bersifat dialogis sangat penting dilakukan, karena lebih efektif bila dibandingkan dengan metode yang lain. Tujuannya adalah untuk menciptakan proses pembelajaran yang efektif. Karena hasil dari komunikasi interpersonal tersebut dapat dilihat dari prestasi siswa, akhlak yang baik, tingkat kepercayaan yang tinggi dan patuh terhadap semua peraturan yang sudah ditetapkan baik di sekolah maupun di tempat bimbingan belajar.

Pola komunikasi antara guru dan siswa adalah pola komunikasi yang terjadi antar pribadi atau interpersonal communication. Hal ini sesuai dengan teori 
yang diungkapkan oleh R.Wayne Pace yang dikutip oleh Hafied Cangara bahwa "interpersonal communication is communication involving two or more people in a face to face setting". Berawal dari sini kemampuan komunikasi interpersonal menjadi sangat penting untuk dapat dipahami dan dikuasai oleh mereka yang mempunyai profesi yang berhubungan dengan orang lain, seperti seorang guru (2005:31).

Guru yang interaktif dan bisa menjalin hubungan komunikasi yang baik dengan siswa dapat membangun suasana belajar yang menyenangkan. Suasana belajar yang menyenangkan berdampak pada kondisi psikologi siswa. Siswa lebih berkonsentrasi, aktif dalam proses belajar mengajar di kelas karena siswa merasa nyaman dan senang. Kuncinya ada pada guru itu sendiri, karena seorang guru harus mempunyai kemampuan komunikasi interpersonal yang baik, agar jalinan komunikasi dengan siswanya menjadi lebih baik pula.

Guru adalah pemimpin pembelajaran, fasilitator, dan sekaligus merupakan pusat inisiatif pembelajaran. Itulah sebabnya, guru harus senantiasa mengembangkan kemampuan dirinya. Selain itu guru juga memiliki standar profesi dengan menguasai materi serta strategi pembelajaran yang dapat mendorong siswanya untuk belajar bersungguh-sungguh. Guru juga harus memiliki kompetensi. Kompetensi guru dapat diartikan sebagai kebulatan pengetahuan, keterampilan dan sikap yang diwujudkan dalam bentuk perangkat tindakan cerdas dan penuh tanggung jawab yang dimiliki setiap guru.

Guru adalah seseorang yang dekat dengan siswa ketika berada di sekolah ataupun di tempat bimbingan belajar. Dengan kedekatan antara guru dan siswa diharapkan guru mampu berkomunikasi interpersonal dengan baik dengan siswa agar mampu mewujudkan siswa yang cerdas dan komunikatif.
Bimbingan belajar menurut Yusuf adalah bimbingan yang diberikan oleh tenaga ahli (konselor) untuk membantu individu dalam menghadapi dan memecahkan masalah-masalah yang berkaitan dengan belajar (2005:23). Ada beberapa alasan siswa mengikuti bimbingan belajar selain sekolah, diantaranya adalah untuk bisa berprestasi dengan hasil yang baik di sekolah sekaligus sebagai tuntutan akademis. Sedangkan harapan orang tua mendukung anaknya untuk mengikuti bimbingan belajar antara lain di samping mengikuti kemauan sang anak, juga dapat meningkatkan kemampuan belajar dan prestasi anak. Dari hasil observasi penulis, tidak semua lembaga bimbingan belajar dapat terbukti efektif. Sebagaimana yang dungkapkan oleh Bray, keefektifan lembaga bimbingan belajar swasta banyak tergantung pada sifat dari bimbingan, motivasi dan kemampuan tenaga pengajar, struktur serta konteks dari sistem pendidikan (2006).

Perkembangan bimbingan belajar atau bimbel ini, tidak hanya terjadi di kotakota besar saja tetapi juga di kota Bengkulu. Seperti Primagama, Ganesha, Talenta, dan Onma. Salah satu bimbingan belajar yang ada di Kota Bengkulu adalah Onma. Yayasan Onma adalah sebuah lembaga yang bertujuan untuk membantu pemerintah guna mewujudkan masyarakat yang memiliki nilai kompetitif di dunia pendidikan dan pasar kerja khususnya di Provinsi Bengkulu. Sampai sekarang lembaga bimbingan yang beralamatkan di jalan Mayjend. Soetoyo No. 25 Kelurahan Tanah Patah Kota Bengkulu masih menjadi salah satu mitra dari Pemerintah Provinsi dan Pemerintah Kota Bengkulu guna mewujudkan Bengkulu Kota Pelajar.

Lembaga bimbingan belajar Onma merupakan salah satu institusi pendidikan yang ada di Kota Bengkulu. Bimbingan belajar seperti Primagama, Ganesha Operation, Talenta dan sebagainya, yang menjadi guru adalah para guru dari 
berbagai sekolah, demikian halnya di Onma, yang menjadi guru juga dari berbagai sekolah SMU di Kota Bengkulu. Siswa yang belajar di Onma juga berasal dari berbagai sekolah SMU di Kota Bengkulu.Siswa yang menjadi fokus penelitian ini adalah siswa bimbel Onma yang tercatat sebagai siswa kelas XII SMU Negeri 05 di Kota Bengkulu.Pemilihan siswa tersebut karena mereka merupakan siswa dari salah satu SMU unggulan di Kota Bengkulu.

Kemampuan dan kepercayaan siswa yang belajar di Onma dipengaruhi oleh kualitas gurunya. Guru yang percaya diri dan memiliki komunikasi interpersonal yang baik dengan siswanya akan membuat siswa lebih cepat menguasai materi pelajaran dan mereka juga memiliki kepercayaan dalam dirinya bahwa mereka mampu untuk menyelesaikan tugas-tugas yang diberikan oleh guru dalam bimbingan belajar.

Hubungan emosional yang responsif antara guru dan siswa-siswanya tergantung pada keberhasilan komunikasi interpersonal seorang guru, yang dapat memiliki pengaruh positif terhadap tingkat kepercayaan siswa. Misalnya dengan sertifikasi, guru SMU memiliki tingkat efektivitas diri lebih baik dibandingkan dengan sertifikat preschool. Guru yang baik akan sangat peduli pada aspek afektif siswanya, sama pedulinya dengan perhatiannya pada perkembangan kognitif dan psikomotorik. Guru yang seperti ini tentu akan membangun akhlak yang baik terhadap siswanya, mengajarinya kasih sayang, mendidik untuk bersikap mulia dan mengajarinya untuk belajar bertanggung jawab.

Kepercayaan merupakan permasalahan yang dihadapi siswa yang berkaitan dengan kegiatan belajar di bimbel Onma. Agar siswa kelas XII SMU Negeri 05 Kota Bengkulu dapat percaya dan termotivasi untuk lebih giat lagi dalam mengikuti proses belajar mengajar yang diterapkan oleh lembaga bimbingan belajar
Onma terhadap siswanya, diperlukan kemampuan interpersonal yang dimiliki oleh guru agar dapat mempengaruhi kepercayaan siswanya terhadap pelayanan mengajar. Dalam hal ini, guru berperan sangat penting dalam meningkatkan kepercayaan siswa terhadap guru bimbingannya.

Berdasarkan latar belakang di atas, maka penulis tertarik untuk menjadikan tingkat kepercayaan pada siswa terhadap gurunya dalam mengikuti bimbingan belajar Onma di Kota Bengkulu sebagai fokus penelitian. Mengingat masih banyaknya siswa-siswa SMU yang ada di Kota Bengkulu belum sepenuhnya memiliki kepercayaan dan akhlak yang baik walaupun di bidang prestasi akademik mereka unggul, seperti siswa SMU Negeri 05 Kota Bengkulu. Jadi penulis akan meneliti pada proses bimbingan belajar kepada siswa melalui komunikasi interpersonal antara guru dan siswa yang hubungannya dengan tingkat kepercayaan yang dimiliki oleh siswa SMU 05 Kota Bengkulu yang sedang mengikuti proses bimbingan belajar di Onma Bengkulu.

\section{METODE PENELITIAN}

Metode yang digunakan dalam penelitian ini adalah metode penelitian fenomenologi. Metode ini dipilih karena peneliti berupaya menggambarkan fenomena komunikasi interpersonal guru dalam meningkatkan kepercayaan siswa pada bimbingan belajar Onma di Kota Bengkulu berdasarkan pendekatan efektifitas komunikasi interpersonal. Tradisi fenomenologi menurut Creswell adalah "Studi dengan pendekatan fenomenologi dengan demikian, berupaya menjelaskan makna pengalaman hidup sejumlah orang tentang suatu konsep atau gejala, dalam hal ini komunikasi interpersonal yang ditunjukkan oleh guru dalam meningkatkan kepercayaan siswa pada bimbingan belajar Onma di Kota Bengkulu, termasuk di dalamnya 
efektifitas komunikasi interpersonal guru kepada siswa.

Moleong menjelaskan bahwa fenomenologi tidak berasumsi bahwa peneliti mengetahui arti sesuatu bagi orang-orang yang sedang diteliti oleh mereka. Mereka berusaha untuk masuk ke dalam dunia konseptual para subjek yang ditelitinya sedemikian rupa sehingga mereka mengerti apa dan bagaimana suatu pengertian yang dikembangkan oleh mereka di sekitar peristiwa dalam kehidupan sehari-hari (2002: 9).

Sementara itu, Littlejohn menyebutkan, "Fenomenologi menjadikan pengalaman hidup yang sesungguhnya sebagai data dasar realitas” (1996: 204). Lebih jauh Littejohn menjelaskan, bahwa fenomenologi berarti membiarkan segala sesuatu menjadi nyata sebagaimana aslinya, tanpa memaksakan kategorikategori peneliti terhadapnya. Seorang fenomenolog tidak pernah membuat hipotesis, tetapi menyelidiki dengan saksama pengalaman langsung yang sesungguhnya untuk melihat bagaimana tampaknya. Dengan metode fenomenologi ini peneliti akan menggambarkan implementasi komunikasi interpersonal guru bimbingan belajar Onma di Kota Bengkulu dalam meningkatkan kepercayaan siswa.

\section{Objek Penelitian}

Dalam penelitian ini obyek peneilitian adalah siswa yang belajar di bimbingan belajar Onma di Kota Bengkulu. Penentuan informan dilakukan berdasarkan hasil pengamatan awal, agar dalam pembuatan pedoman wawancara harus benar-benar memperhatikan informan sehingga tidak terjadi salah pengertian karena kurang tepatnya pertanyaan yang disusun.

\section{Teknik Pengumpulan Data}

Dalam penelitian ini, data yang diperlukan meliputi data bersifat primer dan sekunder. Data yang bersifat primer adalah data yang diperoleh secara langsung dari informan yang diteliti, baik yang dilakukan melalui observasi maupun wawancara. Pengamatan dilakukan dengan mendatangi informan penelitian untuk melakukan wawancara.

Wawancara dalam penelitian bertujuan untuk mengumpulkan keterangan dalam suatu masyarakat serta pendirian-pendirian mereka. Wawancara dilakukan untuk memperoleh informasi dari informan dan dapat menggunakan bantuan alat komunikasi seperti tape recorder atau handycam. Wawancara mendalam merupakan suatu cara mengumpulkan data atau informasi dengan maksud mendapat gambaran lengkap tentang topik yang diteliti.

Dokumentasi juga digunakan oleh peneliti untuk melengkapi dan memperkuat data yang telah diperoleh dari observasi dan wawancara. Data yang dimaksud di sini adalah dokumentasi berita, foto dan rekaman audio visual. Data yang meliputi arsip-arsip dan monografi dipergunakan untuk menguatkan keberadaan data yang telah diperoleh di lapangan melalui proses observasi, dokumentasi dan wawancara.

\section{Teknik Analisa Data}

Pada penelitian ini akan digunakan teknik analisis deskriptif kualitatif yang dilakukan untuk menggambarkan dan menjelaskan proses penelitian. Teknik ini merujuk pada metode analisis yang interaktif dan lebih secara konseptual untuk menemukan, mengidentifikasi, mengelola, dan mengalisis dokumen untuk memahami makna yang sebenarnya. Sesuai dengan sifat dan teknik yang digunakan dalam penelitian ini, maka data atau informasi yang diperoleh menggunakan analisis deskriptif kualitatif 
HASIL PENELITIAN DAN

PEMBAHASAN

\section{Keterbukaan (Openness)}

Dalam melakukan komunikasi interpersonal, terdapat beberapa aspek yang dapat mempengaruhi keberhasilan komunikasi interpersonal tersebut. Setelah melakukan pengamatan dan wawancara terhadap komunikasi interpersonal guru dan siswa dalam meningkatkan kepercayaan siswa terhadap guru di bimbingan belajar ONMA Kota Bengkulu, maka penulis dapat mengaitkan hasil penelitian dengan teori De Vito dalam Liliweri (1997), yaitu ada beberapa aspek yang harus diperhatikan oleh pelaku komunikasi interpersonal, pertama adalah aspek keterbukaan. Keterbukaan yaitu keinginan untuk membuka diri dalam hal berinteraksi dengan orang lain. Penulis dapat melihat bahwa antara guru dan siswa sudah terbangun komunikasi interpersonal yang bersifat terbuka dan penuh kasih sayang antara satu sama lain karena di antara mereka sudah terbangun chemistry yang erat. Siswa bimbel ONMA merasa sangat percaya dengan masing-masing guru yang mengajarinya, mereka tidak meragukan lagi kemampuan guru yang mengajar di ONMA, karena mayoritas guru yang mengajar di sana adalah guru di sekolah negeri terkemuka di Kota Bengkulu. Para siswa juga sangat terbuka jika ada permasalahan yang mereka hadapi dalam menjawab soal. Cara guru menjawab permasalahan mereka juga bisa diterima dengan sangat baik.

\section{Empati}

Empati diartikan sebagai kemampuan untuk mengetahui apa yang dirasakan oleh orang lain. Dalam hal ini, masing-masing informan dalam hal ini beberapa siswa di bimbel ONMA sebagian bisa dikatakan kurang memiliki rasa empati terhadap orang lain, terutama guru karena merasa ragu dengan kemampuan guru dalam memberikan materi dan menjawab soal. Bukan berarti mereka sama sekali tidak peduli dengan apa yang dirasakan orang lain, tetapi tingkat kepekaannya yang masih terbilang kurang jika dibandingkan dengan siswa yang lainnya. Tetapi jika dibandingkan antara kedua informan penulisan ini, Kurnia memiliki rasa empati yang lebih dibandingkan dengan Agus. Namun rasa empati ini masih bisa terus ditingkatkan dengan cara mengajarkan mereka teknik menguasai soal dengan baik dan menjawab soal dengan cepat sesuai dengan waktu yang diberikan.

\section{Dukungan (Supportiveness)}

Aspek ketiga dari komunikasi interpersonal adalah dukungan atau supportiveness. Dukungan yang dibutuhkan oleh siswa yaitu dukungan moral yang diberikan oleh guru di bimbel ONMA. Dengan adanya dukungan dari orang-orang terdekatnya di tempat bimbel terutama guru yang mengajar, maka proses komunikasi interpersonal yang terjalin dalam meningkatkan kepercayaan siswa terhadap guru di bimbel ONMA Kota Bengkulu. Para guru dapat memberikan respon yang positif dan membuat mereka merasa percaya diri karena mereka merasa mendapat dukungan dari siswa yang mempercayakan ONMA sebagai tempat bimbingan belajar mereka.

\section{Perasaan Positif (Positiveness)}

Sikap positif dalam komunikasi interpersonal berarti bahwa kemampuan seseorang dalam memandang dirinya secara positif dan dapat menghargai orang lain. Sikap positif yang ditunjukkan siswa terhadap guru dalam komunikasi interpersonal yang terjalin di antara mereka yaitu dengan memberikan kepercayaan dalam hal lebih terbuka menanyakan soal dan bertanya mengenai jawaban soal yang diberikan oleh guru, sehingga guru lebih percaya diri dalam memberikan jawaban atau menjawab pertanyaan yang dilontarkan oleh siswa selama proses belajar berlangsung. 


\section{Kesamaan (Equality)}

Kesamaan berarti kita dapat menerima dan merasa sama dengan orang lain. Dalam hal ini, guru harus memposisikan dirinya sebagai teman dekat dari siswa. Mereka harus bisa menciptakan komunikasi interpersonal yang baik. Guru sebagai seorang pendidik sudah mengabdi untuk membimbing dan mengarahkan siswa agar bisa menjadi orang yang bermanfaat bagi orang lain. Komunikasi yang dibangun tidak lepas dari rasa kasih sayang, saling keterbukaan, dan rasa kepercayaan antara satu sama lain. Dari komunikasi interpersonal yang terjalin antara guru dan siswa, maka sudah terbangun kedekatan emosi di antara mereka. Dengan terbangunnya kedekatan emosi tersebut maka lebih mudah bagi guru untuk memahami karakteristik anak didik mereka masing-masing. Mereka juga sudah mengetahui trik/cara-cara yang dapat dilakukan untuk menghadapi pertanyaan siswa yang tidak tentu, mulai dari bagaimana cara siswa fokus dalam belajar, cara menjaga kestabilan emosi dan mood siswa, serta metode pengajaran yang tepat dilakukan di dalam kelas.

\section{PENUTUP}

\section{Kesimpulan}

Adapun hasil yang dapat penulis simpulkan dalam penulisan ini yaitu sebagai berikut, jika dilihat dari komunikasi interpersonal yang terjadi antara guru dengan siswa pada bimbel ONMA Kota Bengkulu, masing-masing informan penelitian mempunyai kedekatan yang sangat erat dengan masing-masing gurunya karena dalam proses belajar mereka hanya diajarkan oleh satu orang guru saja. Hal ini yang membuat chemistry di antara mereka semakin erat dan keterbukaan komunikasi yang terjalin cukup baik layaknya orangtua dan anak. Komunikasi interpersonal yang terjalin di antara mereka didukung dengan adanya rasa keterbukaan, dan saling percaya antara satu sama lain. Peran guru di bimbel
ONMA Kota Bengkulu sangat membantu orangtua dalam mengembangkan bakat dan kreativitas yang dimiliki siswa. Orangtua dan siswa sepenuhnya mempercayakan kepada guru untuk bisa membantu perkembangan belajar anaknya.

\section{Saran}

Adapun saran yang dapat di kemukakan dalam penelitian ini adalah sebagai berikut ;

1. Diharapkan untuk guru agar terus menjalin kedekatan dan komunikasi yang baik dengan masing-masing siswa. Tidak hanya kepada siswa yang mereka ajarkan saja, tetapi kepada seluruh siswa yang akan menjadi calon siswa di ONMA Kota Bengkulu sehingga dalam hal penguasaan materi pelajaran yang akan menjadi bahan ujian nasional oleh guru bisa lebih mudah menjawab pertanyaan siswa.

2. Kompetensi guru dalam mendidik dan mengajari siswa di bimbel agar lebih ditingkatkan lagi untuk memahami kebutuhan dan keinginan siswa yang memilih belajar di ONMA Kota Bengkulu. Dalam hal ini guru dituntut untuk menjalin hubungan yang lebih bersahabat dan dekat dengan siswa agar keterbukaan komunikasi antara guru dan siswa dapat terjalin dengan baik dan lancar

\section{DAFTAR PUSTAKA}

Bray M. 2006. Private Supplementary Tutoring: Comparative Perspective on Patterns and Implication. UNESCO International Institute for Educational Planning 3694):515530

Cangara, Hafied, 2005. Pengantar Ilmu Komunikasi. PT. Raja Grafindo Persada, Jakarta, 2004

Devito, Joseph. 2011. Komunikasi Antar Manusia. Terjemahan Agus Maulana \& Lyndon Saputra. Jakarta: Profesional Books 
Devito, Joseph. 2012. Komunikasi Antar Manusia. Terjemahan Agus Maulana \& Lyndon. Saputra. Jakarta: Profesional Books.

Moleong, Lexy. 2006. Metodelogi Penelitian Kualitatif. Remaja Rosda Karya, Bandung.

Littlejohn, Stephen W.1996, Theories of Human Communication, Belmont, California: Wadsworth Publishing Company.
Liliweri, Alo. 2015. Komunikasi Antarpersonal. Rosdakarya. Bandung

Rakhmat, Jalaludin, 2008. Metode Penelitian Komunikasi. Rosdakarya. Bandung.

Qismullah, Yusuf, at.all, (2004). Model Pendidikan dan Pembinaan Guru di Provinsi NAD, Banda Aceh: Majelis Pendidikan Daerah. 